\title{
A Administração do Material e o Planejamento de Compras
}

HUMBERTO LEAL VIEIRA

Técnico de Administração

\section{CONCEITO E POSIÇÃO DA ADMINISTRAÇÃO DO MATERIAL}

Em tôda e qualquer emprêsa existem três atividades básicas: atividades de assessoramento, atividades-meio e atividades-fim. Alguns autores incluem ainda atividades quase-fim ${ }^{1}$.

As atividades de assessoramento são aquelas relacionadas a: estudos, pesquisas, planejamento, aconselhamento etc. exercidas por assessôres e assistentes. As atividades-fim são as responsáveis pela realização dos objetivos da emprêsa e variam em função do propósito da instituição ou da firma. Assim, numa organização hospitalar os serviços de cirurgia, de ginecologia, de pediatria etc. constituem atividades-fim, enquanto em uma emprêsa de produção de bens, o departamento de fabricação ou de produção constitui unidade de atividade-fim.

As atividades-meio são aquelas responsáveis em propiciar condições para a realização dos fins, dos objetivos da emprêsa. Em verdade nenhuma emprêsa pode funcionar sem pessoas que trabalhem, sem material, sem recursos financeiros etc. Essas atividades de pessoal, de material, financeiras etc. representam o grupamento de atividades que comumente chamamos de atividades-meio.

A administração de material - compra, armazenamento, contrôle e distribuição de material - constitui uma atividademeio da administração.

Pelo exposto, podemos concluir que administração de material é uma atividade-meio responsável pela previsão, especificação, aquisição, recebimento, estocagem, conservação, distribuição ou suprimento, venda de excedentes, análise e contrôle de inventários, de material numa emprêsa.

Onde se localiza o órgão de material na emprêsa?

1. TORNAGHI, Newton - Princípios de Organização, Caderno n: 3 Edições Newton Tornaghi - Rio de Janeiro, GB - 1968. 
Depende da natureza e tamanho da emprêsa. Assim, numa emprêsa de produção de bens, a administração de material tem um papel preponderante em virtude de se encarregar da compra de matéria-prima para fabricação do produto final e, nesse caso, geralmente o órgão de material integra a estrutura do departamento de produção. Numa emprêsa de serviços, a atividade de material está ao lado das demais atividades-meio, subordinada ao Departamento de Administração.

\section{IMPORTÂNCIA DA ADMINISTRAÇÃO DO MATERIAL}

A administração de material constitui, ao lado da administração de pessoal e administração financeira, o suporte das atividades-fim da emprêsa. Andrew Carnegie, usando de uma figura para definir essas três atividades fundamentais, pergunta: "Num tripé qual o pé mais importante?" Se não bastassem essas considerações podemos dizer que, segundo alguns estudiosos, $3 / 4$ dos recursos de uma emprêsa estão representados por material ${ }^{2}$.

$\mathrm{Na}$ realidade ninguém pode desconhecer a importância da administração do material para a emprêsa se consideramos que grande parte de seus recursos são empregados, diàriamente, na compra e manutenção de material.

Apesar dessa importância, nem sempre a administração de material é vista como uma das principais atividades em nossas emprêsas e instituições. A nosso ver, vários fatôres concorrem para êsse fato. A pouca publicação sôbre o assunto, a dificuldade de encontrar pessoal capacitado e treinado para as atividades de material fazem com que a função de material seja a "pedra no sapato" de muitos empresários.

Por outro lado, as vultosas economias que se podem conseguir com o emprêgo de técnicas e métodos visando a racionalização de compras, de armazenagem e distribuição de material justificam, por si só, o emprêgo de pessoal capaz e treinado para dirigir um órgão de material. A dificuldade está muitas vêzes onde conseguir êsse pessoal e como proporcionar meios para seu aperfeiçoamento em face da escassez de recursos humanos e de publicações especializadas. Recentemente essa lacuna vem sendo preenchida graças às escolas de administração e cursos diversos, mas ainda longe se encontram de atender à demanda do mercado.

2. SEQUEIRA DE ARAÚJO, Jorge - Administração de Materiais - Editôra Atlas S.A. - São Paulo - 1969. 


\section{ORGANIZAÇÃO DOS SERVIÇOS DE ADMINISTRAÇÃO DO MATERIAL}

\section{1 - Estrutura}

A estrutura interna de qualquer órgão é diretamente proporcional ao seu volume de trabalho, levando-se em consideração a mecanização existente, a racionalização administrativa e sobretudo a especialização do pessoal.

Às vêzes ouve-se falar em regimento padrão ou estrutura padronizada para um conjunto de atividades, como, por exemplo, para o órgão de material. Se a coisa fôsse tão simples, como parece à primeira vista aos menos avisados, não constituiria problema a organização de serviços como o de material, de pessoal, etc., pois bastaria copiar de um manual de organização de uma emprêsa " $A$ " a estrutura ali existente para a emprêsa ou instituição "B". Acontece que, embora êsse procedimento tivesse sido adotado por alguns "entendidos", o resultado, na prática, foi desalentador com tais regimentos padrões. Dificilmente uma emprêsa tem as mesmas condições de uma outra para suportar a mesma estrutura organizacional.

Uma comparação simples nos dá uma idéia. Um sapateiro que pretendesse padronizar os tipos e tamanhos de sapatos e para tanto fizesse uma pesquisa entre mil fregueses, tomando a medida dos pés de cada um, e encontrasse uma média de 34,5 . Se êsse sapateiro fabricasse os mil pares de sapatos daquele tamanho, certamente não calçava nenhum de seus fregueses, ou apenas um pequeno número que por acaso tivesse sua medida de 34,5 . O alfaiate que queira satisfazer sua clientela não deverá fazer roupas de um só tamanho, sob pena de satisfazer apenas parte de seus fregueses.

Raciocínio idêntico se passa com a estrutura de um órgão. A organização de uma emprêsa há de ser feita sob medida para uma determinada época e à medida que a emprêsa aumenta ou cresce também deve aumentar sua estrutura.

Não queremos com êsses argumentos combater a padronização que, reconhecemos, é de grande valia na moderna administração. Admitimos a padronização de material, padronização de normas etc., mas defendemos que cada órgão, como cada emprêsa, deve possuir sua estrutura projetada, tendo em vista suas particularidades, após análise de trabalho, levantamentos técnicos etc.

Após êsses esclarecimentos iniciais, vejamos possiveis estruturas de um órgão de material. Lembramos mais uma vez 
que sua organização, bem como a denominação das unidades que o compõe, dependem de vários fatôres, entre os quais podemos citar:

a) posição do órgão de material na emprêsa

b) volume de trabalho

c) mecanização de serviços

d) racionalização interna dos serviços

e) diversificação do material a ser adquirido

f) especialização do material a ser estocado e distribuído

g) qualificação do pessoal etc.

Em uma emprêsa de pequeno porte seriam necessárias apenas as seguintes unidades:

- seção de compras

- almoxarifado e

- seção de contrôle

A representação gráfica dessa estrutura seria dada pelo organograma abaixo, fig. 1.

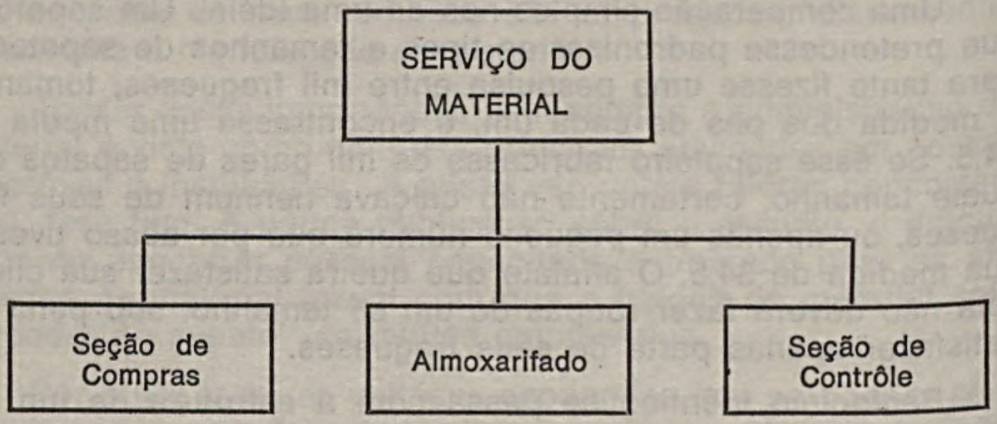

Fig. 1

Uma estrutura de grande porte, para um órgão de material, teria lugar em uma grande instituição. Daremos abaixo uma estrutura bem mais complexa para um órgão de material, com as seguintes unidades:

a) Seção de Programação e Pesquisas de Mercado;

b) Seção de Especificação e Padronização;

c) Seção de Cadastro de Fornecedores;

d) Seção de Licitação;

e) Seção de Importação; 

f) Almoxarifado Geral;
g) Almoxarifado Especializado;
h) Seção de Empenho e Liquidação;
i) Seção de Contrôle de Estoques;
j) Seção de Bens Patrimoniais. tura:

Vejamos na figura 2 a representação gráfica dessa estru-

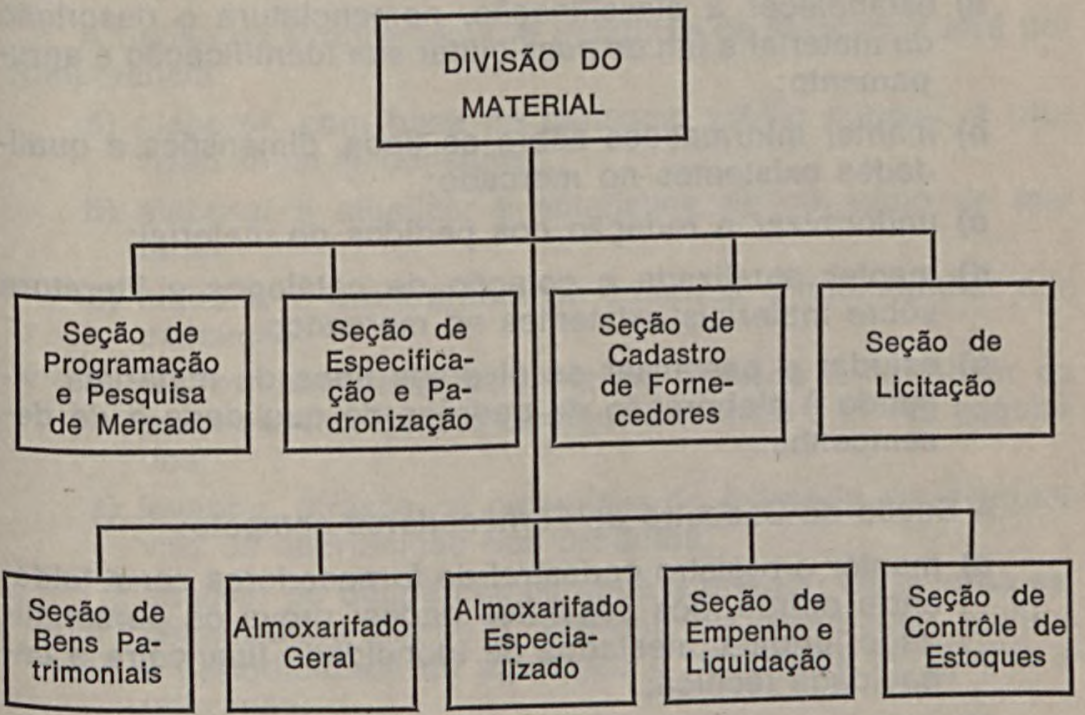

Fig. 2

O contrôle de material permanente embora diga respeito à atividade de material, sua localização tanto pode estar na "Divisão do Material", como pode integrar a estrutura de um órgão financeiro, onde esteja localizada a contabilidade.

A subordinação de um "Serviço de Bens Patrimoniais" ao Diretor do Material é defendida tendo em vista tratar-se de um serviço cuja finalidade é preservação dos bens permanentes da instituição. Ora, ao órgão de material é que deve caber o contrôle e a manutenção de todo o material.

Por outro lado é inegável que para apresentação do balanço anual é de suma importância sua localização no órgão de contabilidade. Ainda as taxas de depreciação ou de valorização, a incidência sôbre o valor histórico das taxas de valorização da moeda, índices de correção monetária etc. são assuntos que interessam à Contabilidade. 


\section{2 - Atividades}

Embora haja uma série de atividades comuns aos órgãos de material, outras, porém, dependem da complexidade da instituição e de seus processos de trabalho.

Assim, a um Serviço ou Seção de Especificação e Padronização deve competir:

a) estabelecer a classificação, nomenclatura e descrição do material a fim de possibilitar sua identificação e agrupamento;

b) manter informações sôbre os tipos, dimensões e qualidades existentes no mercado;

c) uniformizar a redação dos pedidos de material;

d) manter atualizada a coleção de catálogos e literatura sôbre materiais existentes no mercado;

e) estudar e pesquisar os diversos tipos de materiais, visando à elaboração de padrões de qualidade e de desempenho.

A Seção de Cadastro de Fornecedores compete:

a) manter o registro cadastral de fornecedores constituído, entre outros, dos seguintes dados: prova de personalidade jurídica, atestados de idoneidade financeira e capacidade técnica;

b) manter registros, entre outros, dos seguintes dados: nome e enderêço dos sócios responsáveis, capital registrado, enderêço da sede e da representação local, com nome e enderêço dos respectivos gerentes, relação do material que se propõe vender etc.

c) manter atualizado o enderêço de vendedores ou pessoas que devam entrar em contato com a instituição, para efeito de resolver dúvidas ou prestar informações pela Firma;

d) manter o "dossier" individual de cada fornecedor com cópia de tôda correspondência enviada ou recebida;

e) manter um fichário de fornecedores com representação exclusiva, ou que seja o único fabricante de determinado produto;

f) solicitar às firmas e guardar, em seu "dossier" individual, a documentação comprovante de exclusividade; 
Uma Seção de Licitação, ou uma Secretaria da Comissão de Licitação terá por atividades:

a) elaborar os editais de tomada de preços e concorrência;

b) datilografar os convites e expedi-los;

c) abrir as propostas apresentadas pelos fornecedores, com a presença dêstes, quando possivel;

d) elaborar os mapas comparativos de preços;

A Seção de Programação e Pesquisa de Mercados terá por competência:

a) elaborar, com base no consumo médio mensal, a previsão anual de consumo;

b) elaborar e atualizar a estatística de consumo de material;

c) elaborar o cronograma de compras e acompanhar sua execução;

d) realizar pesquisas de mercado visando a conhecer os preços correntes dos diversos materiais a serem adquiridos;

e) levantar, através de pesquisas de mercado, as diversas vias de distribuição dos produtos;

f) analisar os dados cadastrados e orientar os setores especializados quanto à conveniência econômica, técnica e periodicidade de aquisição e condições de guarda e utilização;

g) calcular os lotes econômicos de compra e as épocas de melhores condições de mercado para aquisição;

h) realizar estudos visando a determinar tipos de materiais a serem estocados;

i) manter o contrôle de estoques para fins de reprogramação, se fôr o caso.

Ao Almoxarifado competirá:

a) receber, conferir e examinar e, quando fôr o caso, por intermédio de amostragens, o material recebido;

b) manter o contrôle de estoques máximo e mínimo;

c) apreciar os pedidos de compra de material para efeito de verificação de estoques;

d) fazer o registro da movimentação mensal da entrada e saída de material, discriminando o custo, procedência, destino e saldo; 
e) reclamar aos fornecedores o material dentro do prazo estabelecido, comunicando aos mesmos a falta do material ou incorreção de especificações verificadas quando da entrega;

f) promover a armazenagem do material de acôrdo com sua classificação;

g) proceder à entrega de material aos diversos órgãos;

h) guardar e controlar amostras de material.

\section{FUNÇÕES BÁSICAS PARA O PLANEJAMENTO DE COMPRAS}

\section{1 - Especificação de material}

Especificar material constitui uma arte e uma técnica capazes de exprimir um padrão de maneira a torná-lo claramente conhecido pelo vendedor, pelo comprador, pelo fiscal e pelo consumidor.

O ilustre professor Vitorino Moreira assim conceitua: "por especificação entendemos a descrição perfeita de alguma coisa, onde fiquem perfeitamente indicados os pontos essenciais a todos os detalhes que se façam indispensáveis, a fim de ser possivel a identidade de dois ou mais objetos havidos por meio dessa descrição". ${ }^{3}$

"A especificação deve ser dirigida de forma técnica e terá de conter indispensàvelmente $a$ indicação de dados numéricos relativos aos índices físicos da coisa descrita". ${ }^{4}$

É de real importância para a administração do material a correta especificação. Em verdade, se desejássemos adquirir uma máquina de escrever, logo teríamos de saber: elétrica ou manual? de carro grande ou de carro pequeno? com tipo paica ou elite? etc., etc. A descrição dessa máquina com êsses dados ou outros mais detalhados é que se chama especificação.

Qual a vantagem da especificação para compra? Imaginemos que fizéssemos uma tomada de preços para aquisição de máquinas de escrever e que não oferecêssemos melhores detalhes. Certamente vários tipos de máquinas seriam oferecidos: máquinas mecânicas, elétricas, de carro grande e de carro pequeno, com tipo paica e tipo elite etc. Pode ser que nenhum dos tipos oferecidos seja aquêle que desejamos adquirir. No

3. VITORINO MOREIRA, Oscar - Administração do Material, 2 vols. DASP - Serviço de Documentação - Departamento de Imprensa Nacional, 1967.

4. Idem. 
caso, necessitaríamos de um tipo portátil e não tivesse sido oferecido pelos concorrentes. Teríamos, certamente, perdido todo o trabalho e tempo com a tomada de preços!

Agora vejamos outra hipótese. Dos tipos oferecidos um satisfaz às exigências para o trabalho a ser realizado e, por sinal, é o de menor preço apresentado por um dos concorrentes. Não há dúvida de que êsse concorrente ganhou a licitação, pois foi o preço mais baixo cotado. Imediatamente os demais concorrentes que tenham o produto similar reclamariam, entre outros, com os seguintes argumentos: temos dessa máquina de melhor qualidade e menor preço que o cotado; nosso produto é superior etc. E pode até ser que tenham razão e nós cometeríamos um duplo êrro por conta de uma especificação errada ou incompleta: de um lado, compraríamos um produto de qualidade inferior e mais caro, de outro lado, não demos possibilidade a que todos os fornecedores cotassem o mesmo produto ou similar. Poderíamos até ser acusados que assim procedemos para falsificar uma tomada de preços: pois antes de realizá-la sabíamos o tipo de máquina que seria adquirido e informamos a um dos fornecedores, que cotou o material pelo melhor preço que lhe convinha.

Uma série de inconvenientes surge quando a especificação não é feita em base técnica. Se para a compra de um produto conhecido, como uma máquina, vimos que há uma série de problemas, imaginemos para outros materiais menos vulgares, um aparelho de eletroencefalografia, por exemplo!

Por especificação de material não se entende a transcrição das especificações oferecidas em catálogos de fabricantes, por mais bem feitas que sejam. Essas especificações servem para uso do vendedor. Se formos nos limitar a copiar as especificações de um determinado fornecedor para um determinado material caímos no risco de fazer a chamada "especificação dirigida" que pode constituir vício no processamento de compras.

Duas instituições existem entre nós que cuidam de elaborar especificações técnicas e que muito têm contribuído para o desenvolvimento de nossa indústria. São elas o Instituto $\mathrm{Na}$ cional de Tecnologia (INT) e a Associação Brasileira de Normas Técnicas (ABNT).

O Instituto Nacional de Tecnologia, reformulado pelos Decretos nọs $778 / 38$ e 1.184/39, tem a seu cargo a realização dos ensaios e exames necessários à formulação das especi- 
ficações, padronização e recebimento de material destinado aos serviços públicos federais.

A Associação Brasileira de Normas Técnicas, fundada em 28-9-40, tem como objetivo essencial, definido no art. 1 ? de seus Estatutos, "elaborar, trabalhando também por sua edição e difusão, as normas técnicas brasileiras:

a) para estabelecer especificações destinadas a definir a qualidade e regular o recebimento de materiais;

b) para uniformizar métodos de ensaio;

c) para codificar regras e prescrições relativas a produtos e execução de obras;

d) para fixar tipos e padrões de produção industrial;

e) para unificar e fixar terminologia e símbolos".

Além dessas indicações, o técnico ou órgão encarregado de especificar material para compra deverá manter seu fichário atualizado com indicações precisas sôbre o grupo e subgrupo de material. Abaixo, apresentamos um môdelo de ficha para uso da Seção de Especificação:

Grupo

Subgrupo

Código

Nome do material

Especificação

Fornecedores

Catálogo

No modêlo de ficha acima temos as seguintes indicações: Grupo - que pode ser indicado pela sua denominação ou por código quando houver. Exemplo:

01 - Material permanente de escritório

02 - Material de consumo para escritório

03 - Material cirúrgico 
04 - Aparelhos e instrumentos

05 - Medicamentos

06 - Material de penso etc.

Subgrupo - conjunto de material da mesma família que forma um grupo e também pode ser inscrito na ficha com a denominação ou com o código. Exemplo:

01.001 - Mesa de escritório

01.002 - Cadeira

05.001 - Antibiótico

05.002 - Antitérmico e analgésicos

05.003 - Cardiotônicos etc.

Código - do material é o número a que corresponde o material cuja especificação se encontra na ficha, exemplo:

01.001 .001 - Mesa de aço para datilógrafo, medindo aproximadamente $80 \mathrm{~cm}$ de altura, tampo retangular em aço, revestido em laminado plástico cinza liso, circundado por friso de aço inoxidável, medindo aproximadamente $95 \times 50 \mathrm{~cm}$, gaveteiro com três gavetas laterais de aço, medindo aproximadamente 34 $\mathrm{cm}$ de comprimento, $31 \mathrm{~cm}$ de altura e 38 $\mathrm{cm}$ de profundidade; laterais e fundo da mesa completamente fechados em chapas de aço cinza-linho.

$\mathrm{Na}$ composição do código do material temos indicado o grupo, o subgrupo e o material especificado. Assim, no exemplo acima temos:

01 - Indicador do grupo, no caso material permanente de escritório;

$$
\begin{gathered}
01.001 \text { - subgrupo - mesa de escritório } \\
01.001 .001 \text { - material - mesa de aço } \\
\text { para datilógrafo }
\end{gathered}
$$

No modêlo de ficha apresentado consta ainda lugar para inscrição do nome do fornecedor (fabricante) e o catálogo em que pode ser encontrado o material.

Resumindo, podemos dizer que o trabalho de especificaÇão requer técnica e é de suma importância numa organização.

\section{2 - Padronização}

"Padrão é tudo aquilo que é tomado como unidade de referência; pode ser um formato, tipo, exemplo ou combinação de 
condições aceitas como uma base de comparação, um critério estabelecido pela opinião pública ou aceitação geral, enfim um modêlo" - L.M. Gilbreth.

"Padronização é o estudo ou implantação de uma "unidade de referência", "uma base de comparação", ou um "modêlo". "Padronização é também realizada sob uma forma mais simples e que consiste na redução, do menor número possivel, das variedades existentes de um determinado artigo... resultando na simplificação de tipos existentes" - Lucílio B. Brito.

A padronização constitui uma exigência dos tempos modernos da fase de industrialização, da fabricação em série. Os benefícios da padronização para a indústria e para o comércio são de tal ordem que às vêzes se tornaria impossível o desenvolvimento de determinados produtos se não houvesse padronização.

Tomemos o exemplo de uma lâmpada elétrica. Já imaginou o leitor se o tamanho e medidas das rôscas não fôssem padronizados? Como iríamos saber qual a lâmpada que substituiria uma que se queimou em nossa residência? Ninguém sai pelo comércio experimentando lâmpada para saber se ela se adapta ao bocal da lâmpada que se queimou. Por que isso? Porque os fabricantes de lâmpadas seguem um padrão oficial. Esse material e tantos outros oficialmente padronizados passam despercebidos em face de já nos havermos acostumado a tal padronização.

Lembra-nos ainda o professor Lucílio Briggs Brito que a padronização reduz o custo de produção por tornar possível a fabricação em série dos artigos; simplifica o armazenamento porque, diminuindo o número de variedades e fixando os tipos, facilita a arrumação dos depósitos; reduz o capital empatado na formação dos estoques; evita enganos nos fornecimentos e permite conseguir menores prazos para entrega dos materiais; proporciona ao consumidor fácil aquisição de peças para substituição, oferece maiores garantias de qualidade.

A manutenção de aparelhos e máquinas, por exemplo, encontra reais vantagens quando êsse material é padronizado. Instituições há, cujas máquinas e aparelhos não são padronizados, gastando somas vultosíssimas com a manutenção de seu material. Em verdade o problema de manutenção se apresenta quando a instituição possui máquinas de diversas marcas ou tipos diferentes. Quando isso acontece, duas alternativas se apresentam para a manutenção: ou contratamos alguém ou alguma firma (ou oficina) para cuidar indiferentemente de tôdas 
as marcas de máquinas, ou contratamos, separadamente, firmas especializadas para cada tipo de máquina.

As duas alternativas são bastante onerosas para a instituição. Se de um lado uma oficina ou mesmo um empregado pode encarregar-se do consêrto e manutenção das diversas marcas de máquinas, de outro corremos o risco de não contarmos com trabalho especializado que cada tipo de máquina requer. Ainda mais, é sabido que essas oficinas polivalentes encontram dificuldades para adquirir peças originais. As fábricas geralmente resistem à venda de peças originais de reposição com receio de serem elas empregadas por pessoas não capacitadas e coloquem em risco o bom conceito do equipamento.

A solução está, a nosso ver, na padronização da frota, na aquisição da mesma marca de máquina que possibilitará, entre outras, as seguintes vantagens:

a) possibilidade de contrato com uma única firma especializada para manutenção, de preferência a própria fábrica da máquina ou seu representante autorizado;

b) menor estoque e menor diversidade de peças de reposição;

c) menor custo administrativo de contrôle (número de fichas, de cálculo de inventário etc);

d) maior facilidade de treinamento de pessoal para manejar a máquina ou aparelho;

e) uniformidade de técnica de uso e identidade de resultados.

Para se conseguir a padronização vários estudos são necessários. Devemos começar pelo estudo de simplificação de tipos, pela especificação correta do material e finalmente pela aprovação do padrão e sua divulgação. É vasto o campo da padronização. Segundo o Yearbook of the American Stands temos:

1) padrões para manter uniformidade nas dimensões de partes comuns de máquinas, equipamentos e aparelhos. Tem por objetivo conseguir a substituição fácil das diversas partes intercambiáveis. Ex.: rôscas de parafusos, suportes de lâmpadas etc.;

2) Padrões de nomenclatura - definição de têrmos técnicos usados nas especificações;

3) padrões fixando características do funcionamento ou performance de máquinas e aparelhos os quais estabelecem valôres-limites e requisitos especiais para funcionamento. Ex.: potência de motor elétrico, velocidade para locomotivas etc. Permitem o emprêgo de máqui- 
nas e motores de marcas e procedências diversas, desde que correspondam aos padrões fixados;

4) padrões de segurança;

5) padrões de instruções;

6) padrões de especificações de qualidade para material em geral;

7) padrões de métodos de ensaios;

8) redução do número de tipos de materiais (tamanho e variedade), à quantidade indispensável às necessidades de utilização - Simplificação.

\section{PROGRAMAÇĀO DE COMPRAS}

\section{1 - $O$ que comprar e em que época}

O planejamento anual e a programação mensal das atividades de material, particularmente das atividades de compra, é um procedimento que se impõe a uma boa administração.

O planejamento e a programação desse tipo de atividade requer o exame e estudo de alguns fatôres que condicionam sua execução. Entre outros, merecem exame especial os seguintes fatôres:

a) programa de desembôlso (programação financeira da emprêsa ou instituição);

b) tipos de materiais ou produtos a serem adquiridos;

c) exame das condições de mercado;

d) processos de distribuição do produto.

A programação financeira da emprêsa vai nos informar das épocas ou períodos em que se dispõe de maiores recursos a fim de aí também se concentrar maior volume de pagamentos de compras efetuadas. Por outro lado, podemos imprimir maior ou menor rotatividade de estoque, dependendo da política financeira da emprêsa, das disponibilidades de espaço para armazenamento e das condições do mercado.

O inventário dos produtos a serem adquiridos constitui trabalho prévio indispensável à programação de compras. Respostas às questões tais como: quais os materiais de consumo a serem adquiridos? e a quantidade de material permanente? A emprêsa fabrica algum material usado em seus serviços? Quais? O custo de produção dêsse material fabricado pela emprêsa é menor que o custo de material a ser adquirido? As garantias do processo de fabricação justificam a fabricação interna do produto mesmo por preço acima do adquirido no mercado? 
O exame das condições de mercado visa a conhecer o comportamento do produto em relação ao mercado consumidor. É sabido que determinados produtos variam de preço em determinadas épocas do ano, dependendo não sòmente de sua maior ou menor procura, mas também de sua maior ou menor oferta. O ponto "ótimo" representado pela época de compra deve ser pesquisado pelo comprador obtendo resposta para as seguintes questões:

- em se tratando de produtos sazonais qual a época de maior produção?

- em caso de importação de material de consumo qual a época favorável à importação?

- o orçamento de meus fornecedores coincide com o ano civil ou são de julho a junho?

- há condições financeiras e espaço para armazenagem suficiente para que se possa aproveitar a baixa de preço nas épocas de maior oferta?

- qual a rêde de intermediários desde a fabricação do produto até o consumidor final? Qual a melhor época de compra a atacadistas e fabricantes?

Estas e outras questões têm de ser resolvidas antes de fazermos uma programação de compras. É sabido que produtos como leite, carne, frutas (gêneros perecíveis em geral) possuem época de maior produção e conseqüentemente nessa época devem ser feito os contratos de fornecimento.

Por outro lado, determinados produtos químicos possuem sua época de importação e quando se trata de produtos controlados apenas em determinados meses do ano podem ser importados. Assim torna-se conveniente adquirirmos êsses produtos no mês mais próximo à importação que distante dessa época, não só para obtermos preços melhores mas também haver garantia de fornecimento no prazo estabelecido.

E importante conhecermos o mês de término de exercício de nossos fornecedores, pois, geralmente nos meses que se aproximam ao final do exercício financeiro, a emprêsa pode oferecer melhores preços, visando aumentar seu volume de vendas ao encerrar seu orçamento anual.

Se possuirmos local para armazenagem e em condições que permitam a conservação de material de consumo e se os juros do capital empatado forem mais baixos que a elevação de preço, nos períodos de menor produção, vale a pena estocarmos para uso futuro.

Um dos fatôres nem sempre levado em consideração, mas que é de importância capital, é o conhecimento da rêde de inter- 
mediários, que permite levar o produto desde a fábrica até o consumidor final. Inicialmente teremos de distinguir dois tipos de intermediários: os intermediários obrigatórios do circuito econômico, que desempenham uma função social e os intermediários fortuitos que, em virtude de não exercerem função econômica no sistema de distribuição, são conhecidos como parasitas, atravesssadores, ou simplesmente intermediários desnecessários.

Entre a fábrica e o consumidor, necessário se torna, na maioria das vêzes, a existência de intermediários (atacadistas, distribuidores etc.). A distribuição dos produtos nem sempre está a cargo das próprias fábricas, mas de agentes credenciados ou firmas concessionárias em todo o território nacional. O que deve ser evitado não são êsses intermediários que desempenham uma função social mas os "atravessadores" que se "penduram" no circuito. Esquemàticamente teríamos:

Acreditamos que êsses intermediários podem ser necessários mas se entre um e outro dêsses, geralmente entre o distribuidor e o varejista ou entre êste e o consumidor, se instalam: dois, quatro, cinco ou " $n$ " intermediários outros, certamente êsses serão os parasitas do sistema. O comprador dos produtos para a emprêsa deve tentar adquirir os produtos tanto quanto possível mais próximo da fábrica, obtendo assim melhores preços.

Alguns produtos têm vendedores varejistas, empregados diretamente da fábrica, ou agentes autônomos de comercialização do produto, para venda direta ao consumidor.

Geralmente na comercialização de produtos alimentícios é que aparecem inúmeros intermediários fortuitos encarecendo desnecessàriamente $\mathrm{o}$ preço de venda final ao consumidor.

5.2 - O calendário de compras e o emprêgo do gráfico de GANTT para programação de compras.

O calendário de compras durante muito tempo foi usado no Serviço Público Federal, graças aos estudos da antiga Divisão do Material do DASP conforme nos dá notícia o ilustre professor Vitorino Moreira. ${ }^{5}$

O calendário de compras compreende:

a) calendário de pedidos;

b) calendário de requisições;

c) calendário de licitações.

5. Idem. 
O material é distribuído em lotes, grupos e classes. $\mathrm{O}$ objetivo do calendário de compras é racionalizar o processamento da administração do material pelo ordenamento das providências relativas a requisições, pedidos, e compras pròpriamente ditas. Pelo calendário, determinados grupos - lotes - de materiais serão requisitados, pedidos ou adquiridos em determinadas épocas prèviamente estabelecidas. $O$ cálculo das quantidades a serem adquiridas está em função do gasto médio mensal e da época em que será feita nova compra.

Modernamente o emprêgo do gráfico de Gantt para programação de compras vem possibilitar as vantagens do calendário de compras e mais outras vantagens como sejam o cálculo de prazo de entrega de material e as variações de estoques máximo e mínimo, além da flexibilidade de prazos e conseqüentemente possibilidade de melhor adaptação às situações de variação de consumo.

A elaboração do gráfico requer não sòmente os requisitos exigidos no calendário de compras (separação do material por grupos e subgrupos, melhor época de compras etc., mas também outros como sejam cálculo da data de nôvo pedido, prazos prováveis de entrega do material, variações de consumo etc.

O cálculo da data do nôvo pedido é feito com o emprêgo da fórmula:

Onde:

$$
X=A-(B+C)
$$

$\mathrm{X}=$ data do nôvo pedido;

$A=$ data provável do estoque zero;

$B=$ ao prazo de entrega do fornecedor;

$\mathrm{C}=$ prazo de consumo do estoque mínimo.

O prazo de entrega do material pelo fornecedor varia de imediato a 6 meses, dependendo da quantidade e da praça onde o material é adquirido:

- a entrega imediata considerada aquela feita logo após a entrega do pedido, demorando apenas o tempo suficiente para embalagem e transporte do material do depósito do vendedor até o depósito do comprador. Esse prazo é concebido no máximo em 8 dias;

- prazo de entrega de 30 a 45 dias é geralmente o prazo de entrega do material adquirido do mercado nacional;

- prazo de entrega de 90 a 120 dias é o prazo normal de entrega de mercadoria comprado no mercado externo que depende de importação; 
- prazo de entrega de 180 dias (6 meses) é o prazo normal de entrega de material adquirido do exterior que dependa de encomenda aos fabricantes.

Êsses prazos não são absolutos, muitas vêzes podemos reduzir de muito, entretanto êles devem ser considerados na programação para elaboração do gráfico o que permitirá folga no processo de reposição de estoques e mais segurança ao sistema.

O comportamento do estoque também deve ser levado em consideração quando fazemos uma programação de compras. Conforme vimos acima materiais há que requerem maior rotatividade de estoque, outros, são adquiridos de acôrdo com sua média de consumo mensal, outros ainda são consumidos em maior quantidade em determinadas épocas do ano etc., etc.

O conceito de estoque máximo e estoque mínimo está ligado a essas variações de estoques.

O estoque máximo é o resultante da aquisição de um lote econômico de compras, isto é, o adquirido, tendo em vista:

- custo da aquisição

- espaço útil ocupado

- juros do capital empatado

- obsolescência

- transporte e manuseio

- deterioração

- política de desembôlso da emprêsa

- comportamento do estoque

- qualidade e natureza do material

O estudo dêsses fatôres vai nos levar a fixar a quantidade máxima de material a ser estocado num determinado período.

O estoque mínimo é aquêle calculado para suportar 0 consumo desde a época do pedido de compra até à chegada do material entregue pelo fornecedor. Embora essa seja a definição aceita para o estoque mínimo, seu cálculo deve guardar sempre uma margem de segurança, isto é, à época da chegada do material fornecido pelo vendedor, ainda deve existir algum estoque como margem de segurança.

Em algumas emprêsas, notadamente em organizações hospitalares, onde a falta de certos materiais poderá causar a morte de pessoas, é conveniente usar-se o estoque de alarme. Este estoque representa a margem de segurança do estoque mínimo.

O estoque de alarme é aquêle compreendido na margem de segurança do estoque mínimo ou, se êste fôr rígido, a porção 
de estoque que vai além do estoque mínimo. Nesse caso, teríamos:

Estoque máximo

Estoque mínimo

Estoque de alarme
- calculado para 6 meses

- calculado para 45 dias

- calculado para 8 dias

O ińcio do estoque mínimo indica a época do pedido do almoxarifado; o seu término indica a época da reposição de estoque ou se essa reposição não se dá, o início do consumo do material considerado no estoque de alarme.

0 estoque de alarme indica a não-reposição do estoque e o início da compra de emergência para que não haja solução de continuidade no funcionamento da emprêsa ou cause danos à vida de pessoas no caso de organização hospitalar.

Tôdas essas considerações são levadas em conta quando programamos as compras através do gráfico de Gantt.

A questão dos prazos de divulgação dos editais, de julgamento, de emissão de empenhos são fatôres importantes na programação. Se a entidade é pública, temos que observar os seguintes prazos mínimos:

- convite: três dias úteis para abertura das propostas

- tomada de preços: 15 dias

- concorrência: 30 dias

- julgamento: dependendo da quantidade de itens e da especialização do material -8 dias

- emissão de empenho: 2 dias (compreendendo emissão prgpriamente dita e assinaturas)

O gráfico de Gantt é traçado com os seguintes dados:

a) conhecimento da época de melhor preço no mercado;

b) conhecimento das disponibilidades financeiras da emprêsa;

c) prazos de estoque máximos;

d) cálculo do estoque mínimo;

e) cálculo do estoque de emergência;

f) prazos de licitação;

g) prazo estimado para julgamento;

h) prazo estimado para emissão do empenho ou ordem de fornecimento;

i) prazo de entrega do material (considerar os prazos de acôrdo com a procedência: nacional ou do exterior). 
5.2.1 - Instruções para elaboração do cronograma de compras

Conhecidos os prazos acima, fácil se torna elaborar o gráfico, observando as seguintes instruções:

1) Trace o gráfico conforme modêlo abaixo. Observe que o ano é dividido em 12 partes iguais que correspondem a 12 meses, com traços mais finos divida cada mês em 4 partes iguais que correspondem a 4 semanas.

2) Do lado esquerdo, deixe espaço suficiente para relacionar os grupos e subgrupos de materiais a serem adquiridos. Do lado direito, após o mês de dezembro, está o espaço reservado às observações.

3) Coloque seu programa no gráfico da seguinte maneira (Vide fig. 4 abaixo):

3.1) Convencione os sinais: por exemplo:

......... época do pedido com especificação;

- prazo de divulgação dos editais;

-...-. prazo de julgamento e emissão de empenho;

-.-.- prazo provável de entrega do material.

3.2) Indique êsses prazos no gráfico. No exemplo dado o grupo de material 3 - máquinas e aparelhos tem os seguintes prazos:

- época do pedido: duas últimas semanas de março e primeira semana de abril;

- prazo de publicação dos editais: três últimas semanas de abril e primeira semana de maio;

- julgamento e emissão de empenho: duas semanas de maio ;

- prazo provável de entrega do material: quatro semanas, última semana de maio e três semanas de junho.

- Observe que procedendo como acima indicado você lançou no gráfico o programa, isto é, a previsão das épocas (semanas) em que acontecerão aquêles eventos.

3.3) Abaixo da programação risque um retângulo de comprimento igual ao programa acima. Êle servirá para ser preenchido à medida que o programa vai sendo executado.

4) Acompanhe a execução de seu programa, anotando as anormalidades verificadas: anțecipação ou adiamento. 
No exemplo da figura 4 estamos na primeira semana de maio (dia 6 ou 7 de maio, o gráfico nos indica até essa data que:

a) o programa do grupo 1 - material de expediente foi totalmente executado, conforme previsto, pois, o retângulo destinado a execução se encontra totalmente preenchido;

b) o mesmo acontece com o grupo 2 - móveis de escritório;

c) o grupo 3 - máquinas e aparelhos - encontram-se na sexta semana de execução, isto é, no término do prazo de publicação dos editais e já vão iniciar a abertura das propostas, julgamento e emissão de empenho;

d) grupo 4 - impressos - não teve seu programa iniciado no meio da semana de maio conforme previsto. Sua execução foi adiada para segunda semana de setembro com término previsto para a última semana de novembro. Nas observações encontramos a explicação para o fato: "adiamento justificado pelo reexame dos modelos para fins de simplificação e padronização";

e) o programa do grupo 5 - material de limpeza foi antecipado em virtude de incêndio no depósito daquele material. Seu início estava previsto para segunda semana de junho e sua execução se deu três meses e meio antes.

O programa assim concebido facilita ao Chefe ou Diretor de Compras. Êste passa a administrar por exceção, isto é, sua interferência no processo só se justifica quando o carro "pega". Correndo tudo normal, não há motivo de sua interferência. $\mathrm{Na}$ medida em que os executores têm conhecimento daqueles prazos e os cumprem, o programa corre normalmente. Se há algum ponto de estrangulamento é necessária a interferência do Chefe para sanar o problema.

A administração de compras, como outras funções da administração de material, para se tornar racional é necessário proceder-se a uma programação. Êsse procedimento não só evita as improvisações como assegura o normal funcionamento da emprêsa.

A administração de material é uma função tão importante na emprêsa que torna o homem encarregado dêsse setor responsável em grande parte pelo sucesso de qualquer empreendimento. 
